\title{
Long term environmental radiological assessment of solid radioactive waste disposal - a case of study
}

\author{
S.S. Peres and E.R.R. Rochedo
}

\begin{abstract}
Instituto de Radioproteçao e Dosimetria, Departamento de Proteçao Radiologica Ambiental, Av. Salvador Allende s/ $n$, Jacarepagua, CEP 22780-160 Rio de Janeiro, Brazil
\end{abstract}

\begin{abstract}
Since the time when the repository for the radioactive wastes from the Goiania accident has been licensed, the uses of surrounding area have changed, leading to different exposure scenarios related to a simulated event of ground water contamination. Other changes can be foreseen for the short-medium term occupation of the surrounding area. Using this situation as an example and considering the simplicity that it deals with only one radionuclide, a probabilistic assessment and an uncertainty study were carried out where the effect of changes on both the exposure scenarios and parameter values have been considered. Results shows that more simulations must be performed when a national low level repository is to be licensed, as land use in developing countries can present significant changes in times of concern even for low level radioactive waste repositories.
\end{abstract}

\section{INTRODUCTION}

Design concepts for radioactive waste repositories rely on a system of multiple barriers to provide isolation of the waste from the biosphere. Nevertheless, permanent total isolation over extend time-scales, is not likely to be achievable and some fraction of mobile long lived radionuclides may be released from ngineered disposal system, ultimately to emerge into the biosphere, potentially giving rise to exposure lindreds years or beyond into the future.

Processes that could lead to human exposures have to be identified on a site-specific basis. Some natural processes, such as the gradual degradation of the waste package, may result in a gradual release of mdionuclides into the environment. Subsequent natural processes, which could lead to human exposure, may include the contamination of groundwater. Future human actions have a strong influence on the radiological impact of any future release. Future actions, mainly human intrusion, may have an effect on, or be a response to prevailing environmental conditions. Prediction of future human habits is extremely difficult, if not practically impossible with any useful degree of reliability. These uncertainties in space and time are a significant challenge for the performance assessment of disposal systems designed to receive long-lived radioactive waste [1].

An important principle in radioactive waste management is that "radioactive waste shall be managed in such a way that predicted impacts on the health of future generations will not be greater than relevant levels of impact that are acceptable today" [2]. It means that waste disposal practices should provide for the protection of both current and future generations, and long-term safety assessments should provide assurance that future impacts are compatible with those accepted today. Therefore, protection of future generations should be achieved by applying these dose or risk criteria to the estimated future doses or isks in appropriately defined critical groups. In the case of these longer time periods, they represent indicators of the protection afforded by the disposal system $[3,4]$.

There are two broad categories of exposure scenarios that have to be considered: natural process and uman intrusion. This paper presents the preliminary results of the study that is being carried out by Institute of Radiation Protection and Dosimetry (IRD) for developing of biosphere modelling that should be applied to performance assessment of long-lived radioactive waste repositories in tropical environments. For the simulation of these conditions, a case study was used. Annual effective doses were calculated being assumed a scenario of use of waters deep well, potentially contaminated in consequence of the $\mathrm{Cs}^{137}$ migration from repository. Deterministic and probabilistic assessments were carried out in order to evaluate the exposure scenarios and parameters of larger contribution to overall variation in alculated dose value. Preliminary results have showed that a wide knowledge of the principal components of the biosphere system is necessary in the licensing, so that the performance assessment of the disposition yystem is carried out. 


\section{METHODOLOGY}

In the assessment context the type of disposal facility under consideration is a near surface repository localised in plain inland as the Abadia Repository in Brazil. In order to simplify, it was assumed that the waste was contaminated only with ${ }^{137} \mathrm{Cs}$, as it is the case of the waste from Goiânia Radiological Accident. Moreover, the gradual degradation of the waste package and engineered barriers were assumed. The human exposure arises from the use of the contaminated well water.

In the beginning of the contamination event, the activity concentration is normalized to $1 \mathrm{~Bq} \cdot \mathrm{L}^{-1}$ of ${ }^{137} \mathrm{Cs}$ in the well water was considered. Three assumptions were assumed for ${ }^{137} \mathrm{Cs}$ activity concentration $\left(\mathrm{C}_{\mathrm{w}}\right)$ behaviour in well water: $\mathrm{Cw}$ remains constant over the assessment period (Case 1); $\mathrm{Cw}$ decreases in time with a decay assumed to be proportional to the radioactive decay of the source term (Case 2); and $\mathrm{CW}_{W}$ increases linearly during the whole assessment period (Case 3).

A farming community whose exclusive source of drinking and irrigation water is the contaminated well water was assumed. The activities and characteristics of the population exploiting the well water were considered similar to those of current communities. The community lives and works in the contaminated site and is capable of providing a major proportion of its dietary requirements from locally produced foodstuffs. The dose assessment for the critical group was carried out up to 300 years, after the ${ }^{137} \mathrm{Cs}$ migration from repository to the ground water. During the assessment time frame, no relevant change of the biosphere components was assumed, although some aspects related to the use of the area are discussed.

The annual individual effective dose was used for assessment of the potential environmental radiological impact. The dose assessment, in this first screening, was restricted to adults as, except for the ingestion pathways, other exposure pathways are related to the work at the area contaminated by irrigation. The use of well water as drinking water, irrigation of food crops and watering cattle is considered. It is also considered the inhalation of resuspended dust and external exposure to the contaminated soil of the agricultural area. The intake of eggs is also considered and hens are assumed to be contaminated by ingestion of locally produced grains.

The soil in the agricultural area in year $t$ is considered to be contaminated by irrigation:

$$
C s(t)=C s(t-1) \cdot \exp ^{-(l s+l r)}+C w(t) \frac{\left[1-\exp ^{-(l s+l r)}\right]}{P \cdot(l s+l r)}
$$

Where:

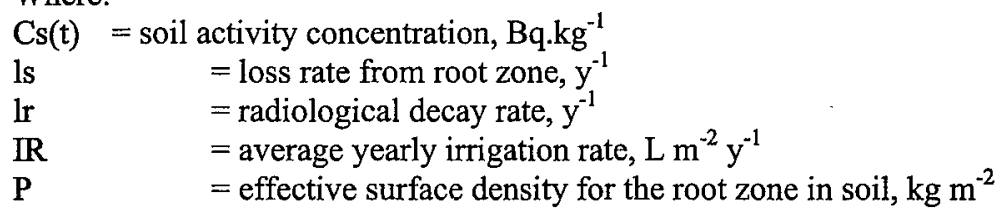

Other equations used in the model assume radioactive equilibrium and follows methodology proposed by the IAEA [7], except for the external exposure where the coefficient proposed by Eckermman [8] has been used. The external dose is considered only related to the work over the soil contaminated by irrigation as the following:

$\operatorname{Dext}(t)=C s(t) \cdot$ Uoutdoor $\cdot F C D e x t$

Where:

Uoutdoor = occupation rate of the contaminated area

FCDext $\quad=$ dose conversion factor for external exposure

Parameter values and statistical data used in this simulation are listed in Table 1. The probabilistic assessment and the uncertainty analysis were performed using the Crystal Ball software [8], with a Latin hypercube sampling procedure and 1000 simulations for each scenario. 
Table 1: Data used on the simulation of biosphere scenario

\begin{tabular}{|c|c|c|c|c|c|c|}
\hline Paraneter & Description & Unis & Distribution & Average & Minimun & Maximum \\
\hline Ls & Loss from root zone in soil & $a^{-1}$ & $\mathrm{Ln}$ & $1,0 \mathrm{E}-02$ & $0,0 \mathrm{E}+00$ & $9,0 \mathrm{E}-02$ \\
\hline $\mathrm{P}$ & effective surface density of soil & $\mathrm{m}^{2} \cdot \mathrm{kg}^{-1}$ & Ln & $2,0 \mathrm{E}+02$ & $1,2 \mathrm{E}+01$ & $1,7 E+03$ \\
\hline $\mathrm{Ir}$ & irrigation rate & $\mathrm{m}^{2} \cdot \mathrm{d}^{-1}$ & $\mathrm{U}$ & $1,0 \mathrm{E}+00$ & $5,0 \mathrm{E}-01$ & $2,0 \mathrm{E}+00$ \\
\hline LV & loss from deposition on leaves & $d^{-1}$ & Ln & $4,6 \mathrm{E}-02$ & $3,0 \mathrm{E}-03$ & $4,0 \mathrm{E}-01$ \\
\hline $\mathrm{Te}$ & growing season & $\mathrm{d}$ & $\mathrm{T}$ & $6,0 E+01$ & $4,6 \mathrm{E}+01$ & $9,0 \mathrm{E}+01$ \\
\hline R/Yveg & retention yield & $\mathrm{m}^{2} \cdot \mathrm{kg}^{-1}$ & Ln & $3,0 \mathrm{E}-01$ & $2,0 \mathrm{E}-02$ & $2,9 \mathrm{E}+00$ \\
\hline RYgrain & retention yield & $\mathrm{m}^{2} \cdot \mathrm{kg}^{-1}$ & Ln & $8,0 \mathrm{E}-01$ & $5,0 \mathrm{E}-02$ & $7,2 \mathrm{E}+00$ \\
\hline R/Yleaf & retention yield & $\mathrm{m}^{2} \cdot \mathrm{kg}^{-1}$ & Ln & $1,0 \mathrm{E}-01$ & $6,0 \mathrm{E}-03$ & $8,6 \mathrm{E}-01$ \\
\hline $\mathrm{Bv}$ & soil-plant transfer factor & - & $\operatorname{Ln}$ & $3,0 \mathrm{E}-02$ & $2,0 \mathrm{E}-03$ & $2,6 \mathrm{E}-01$ \\
\hline Fmeat & transfer coefficient to meat & d. $\mathrm{kg}^{-1}$ & Ln & $2,0 \mathrm{E}-03$ & $1,0 \mathrm{E}-03$ & $1,7 \mathrm{E}-01$ \\
\hline Fmilk & transfer coefficient to milk & d. $\mathrm{kg}^{-1}$ & $\operatorname{Ln}$ & $1,0 \mathrm{E}-02$ & $1,0 \mathrm{E}-03$ & $9,0 \mathrm{E}-02$ \\
\hline Fegg & transfer coefficient to eggs & d. $\mathrm{kg}^{-1}$ & In & $5,0 \mathrm{E}-01$ & $3,0 \mathrm{E}-02$ & $4,3 \mathrm{E}+00$ \\
\hline Uw & water ingestion by cattle & L.d $d^{-1}$ & $\mathrm{U}$ & $5,0 \mathrm{E}+01$ & $4,0 \mathrm{E}+01$ & $7,5 \mathrm{E}+01$ \\
\hline $\mathrm{Ug}$ & grain ingestion by chicken & $\mathrm{kg} \cdot \mathrm{d}^{-1}$ & $\mathrm{U}$ & $1,0 \mathrm{E}-01$ & $9,0 \mathrm{E}-02$ & $1,1 \mathrm{E}-01$ \\
\hline $\mathrm{k}$ & resuspension constant & $\mathrm{m}^{-1}$ & $\mathrm{~T}$ & $1,0 \mathrm{E}-09$ & $1,0 \mathrm{E}-10$ & $1,0 \mathrm{E}-08$ \\
\hline FCDext & dose conversion factor for external exposure & $(\mathrm{Sv} / \mathrm{a}) \cdot(\mathrm{Bq} / \mathrm{kg})^{-1}$ & Ln & $8,1 \mathrm{E}-07$ & $1,8 \mathrm{E}-07$ & $3,0 \mathrm{E}-06$ \\
\hline FCDint & dose conversion factor for ingestion & $\mathrm{Sv} \cdot \mathrm{Bq}^{-1}$ & Ln & $1,4 \mathrm{E}-08$ & $2,9 \mathrm{E}-09$ & $5,0 \mathrm{E}-08$ \\
\hline FCDinh & dose conversion factor for inhalation & Sv.Bq & Ln & $8,6 \mathrm{E}-09$ & $1,9 \mathrm{E}-09$ & $3,2 \mathrm{E}-09$ \\
\hline Cleafy & fraction of consumption of local leafy vegetable & - & $\mathrm{T}$ & $9,0 \mathrm{E}-01$ & $8,0 \mathrm{E}-01$ & $1,0 \mathrm{E}+00$ \\
\hline Creg & fraction of consumption of local vegetables & - & $\mathrm{T}$ & $7,0 \mathrm{E}-01$ & $6,0 \mathrm{E}-01$ & $8,0 \mathrm{E}-01$ \\
\hline Cgrain & fraction of consumption of local grain & - & $\mathrm{T}$ & $5,0 \mathrm{E}-01$ & $4,0 \mathrm{E}-01$ & $6,0 \mathrm{E}-01$ \\
\hline Cmeat & fraction of consumption of local meat & - & $\mathrm{T}$ & $9,0 \mathrm{E}-01$ & $8,0 \mathrm{E}-01$ & $1,0 \mathrm{E}+00$ \\
\hline Cmilk & fraction of consumption of local milk & - & cte & $1,0 \mathrm{E}+00$ & $1,0 \mathrm{E}+00$ & $1,0 \mathrm{E}+00$ \\
\hline Cegg & fraction of consumption of local egg & - & cte & $1,0 \mathrm{E}+00$ & $1,0 E+00$ & $1,0 \mathrm{E}+00$ \\
\hline Cwater & water ingestion rate & L. $\mathrm{a}^{-1}$ & $\mathrm{U}$ & $4,0 \mathrm{E}+02$ & $3,6 \mathrm{E}+02$ & $4,4 \mathrm{E}+02$ \\
\hline Uoutdoor & occupation outdoors & - & $\mathrm{T}$ & $5,0 \mathrm{E}-01$ & $3,0 \mathrm{E}-01$ & $6,0 \mathrm{E}-01$ \\
\hline
\end{tabular}

\section{RESULTS}

Main results are presented on figures 1 to 3 . We can see that for the cases analysed, there is good agreement between the deterministic output and the average probabilistic output, although the deterministic result was usually lower than the corresponding probabilistic value. The dose distribution for each time step shows a nearly lognormal behaviour. This can also be observed for individual dose distributions for all pathways. The relevance of each pathway varies over the short-term period but longterm behaviour was observed in all cases.

The relevance of parameters was found to reflect the relevance of the pathway to which it is related. As so, we can see that, for Case 1 (Figure 1), the most relevant pathways at the first year are the water and vegetables ingestion. The parameters shown to be affecting the total dose reflect the ingestion pathway (FCDing) and those related to the vegetable concentration (irrigation rate, soil density, interception fraction and yield, and loss rate from leaves). For the 100 years output, the build up of activity in soil leading to external exposure supersedes the direct water ingestion pathway and becomes the most relevant pathway. Parameters affecting the total dose at this moment include those related to the soil contamination (irrigation rate and soil density) but also include the dose conversion factor for external exposure.

For Case 2, as the build up of soil concentration is not so effective as in case 1, although external exposure appears as a relevant pathway (19\% of total dose), the 100 years ingestion of vegetables remains as the main pathway ( $63 \%$ of total dose), and the direct water ingestion may still be considered as a relevant pathway ( $15 \%$ of total dose). For Case 3, the same behaviour observed in case 1 can be seen, with increasingly effect of soil concentration build-up on the relevance of the external exposure pathway ( $72 \%$ of total dose). 
Effective dose output
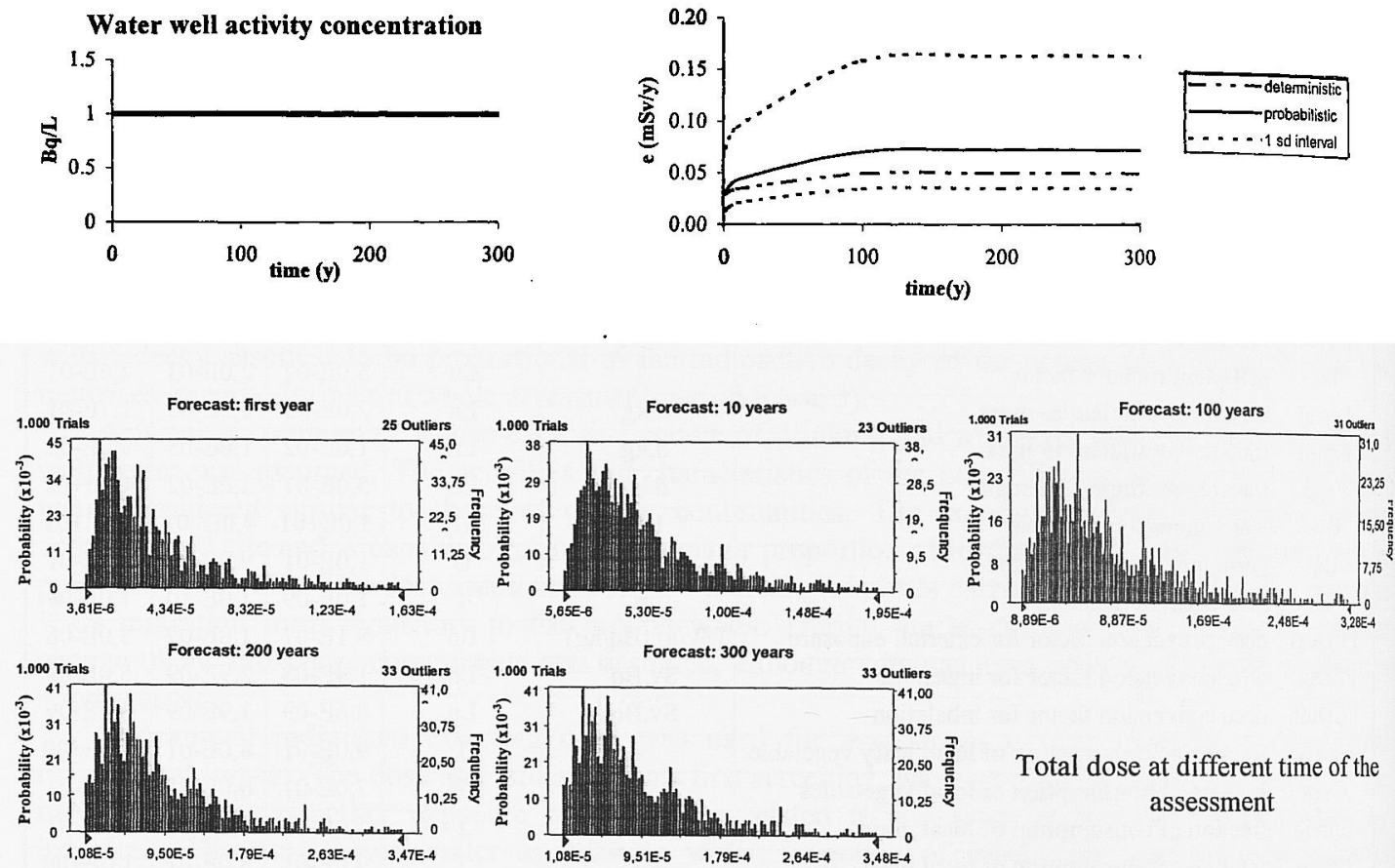

Total dose at different time of the assessment
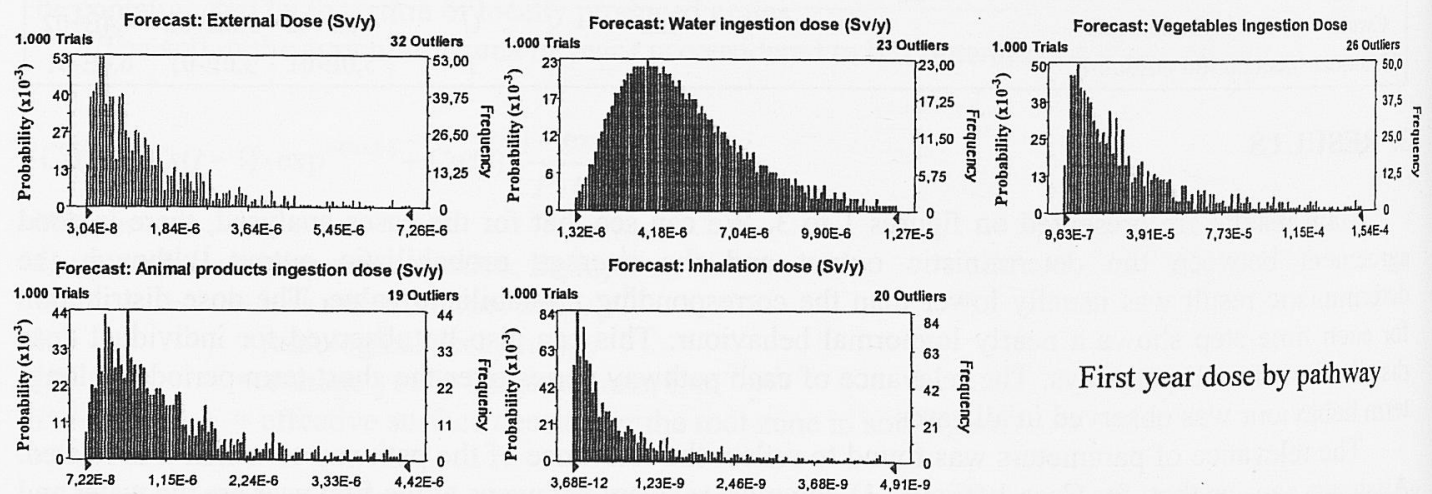

First year dose by pathway

Pathway contribution to total dose

\begin{tabular}{|c|c|c|c|c|c|}
\hline Time (y) & External & Vegetables & $\begin{array}{c}\text { Animal } \\
\text { products }\end{array}$ & Water & Inhalation \\
\hline 1 & $244 \mathrm{E}-02$ & $7.92 \mathrm{E}-01$ & $287 \mathrm{E}-02$ & $1.55 \mathrm{E}-01$ & $3,60 \mathrm{E}-06$ \\
\hline 100 & $4.24 \mathrm{E}-01$ & $4.70 \mathrm{E}-01$ & $1.67 \mathrm{E}-02$ & $9.01 \mathrm{E}-02$ & $6,27 \mathrm{E}-05$ \\
\hline
\end{tabular}

Pathway and parameter

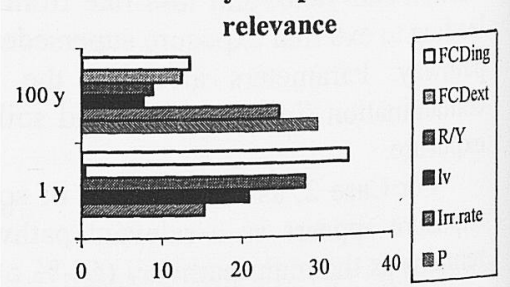

Figure 1: Case 1 assumptions and forecasts 
Water well activity concentration

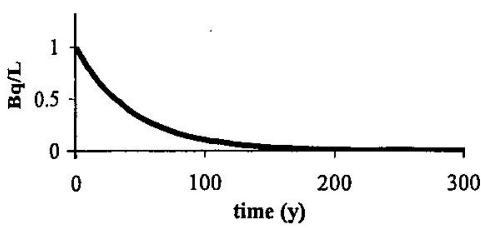

Pathway and parameter relevance

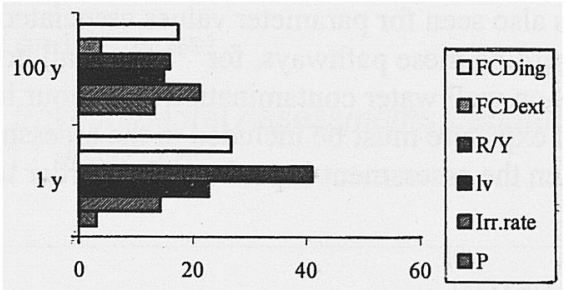

Effective dose output

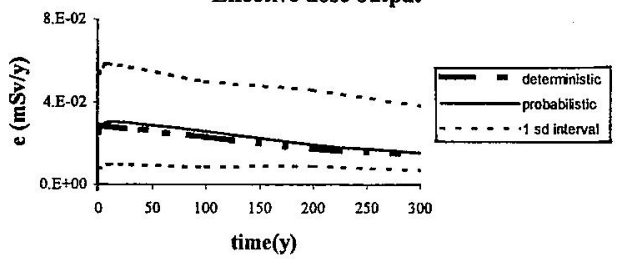

Pathway contribution to total dose

\begin{tabular}{|c|c|c|c|c|c|}
\hline Time $(y)$ & External & Vegetables & $\begin{array}{c}\text { Animal } \\
\text { products }\end{array}$ & Water & Inhalation \\
\hline 1 & 0,02 & $\mathbf{0 , 7 6}$ & 0,03 & $\mathbf{0 , 1 9}$ & 0,00 \\
\hline 100 & $\mathbf{0 , 1 9}$ & $\mathbf{0 , 6 3}$ & 0,03 & $\mathbf{0 , 1 5}$ & 0,00 \\
\hline
\end{tabular}

Figure 2: Case 2 results

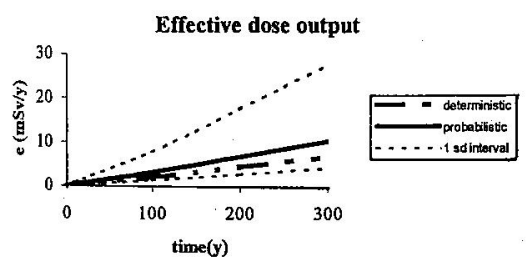

Pathway and parameter relevance

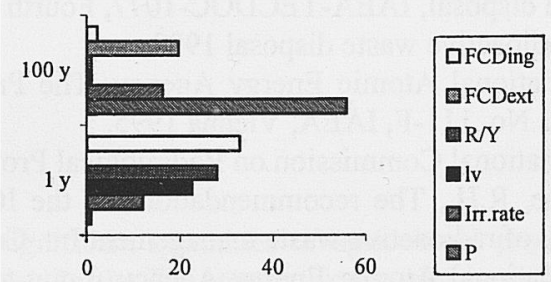

Effective dose output

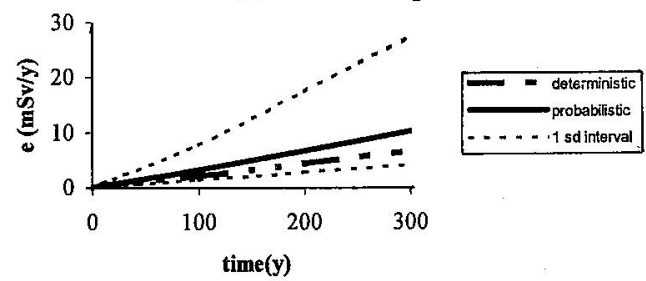

Pathway contribution to total dose

\begin{tabular}{|c|c|c|c|c|c|}
\hline Time $(y)$ & External & Vegetables & $\begin{array}{c}\text { Animal } \\
\text { products }\end{array}$ & Water & Inhalation \\
\hline 1 & 0,02 & $\mathbf{0 , 7 6}$ & 0,03 & $\mathbf{0 , 1 9}$ & 0,00 \\
\hline 100 & $\mathbf{0 , 7 2}$ & $\mathbf{0 , 2 2}$ & 0,01 & 0,05 & 0,00 \\
\hline
\end{tabular}

Figure 3: Case 3 results 
In all three Cases, ingestion of animal derived products had an effect on total dose of less than $1 \%$, and this was also seen for parameter values associated to these pathways. This means that any change of land use regarding these pathways, for ${ }^{137} \mathrm{Cs}$, shall not affect the impact assessment of the repository. The assumptions on well water contamination behaviour in time and land use regarding vegetable production and external exposure must be included in the assessment, even if these are not an actual practice at the moment when the assessment is performed, in order to be sure that future generations will be adequately protected.

\section{CONCLUSION}

Parameter values and scenario variability may be foreseen for the period related to long-term assessments such as those performed to waste repositories. Probabilistic assessment and uncertainty analysis are useful tools to estimate which parameters and pathways are probable to be of concern for present and future uses of the site. From the examples in this work we could see, for $\mathrm{Cs}^{137}$, that the main concern should address external exposure and vegetables ingestion. These pathways should then be considered in the dose assessment, even if these pathways are not available at the moment when the assessment is performed. Main parameters affecting the dose assessment have been pointed as those related to soil properties that might affect the eternal exposure and food crop properties. The determination of such parameters in a site specific approach should be prioritised as a better knowledge on the adequate value would increase the confidence on model predictions.

This kind of analysis will be extended to all radionuclides relevant to the low level wastes from the Angra 1 and 2 nuclear Power Plants. Also the scenario will be designed to fit the seashore site foreseen for that waste repository.

\section{References}

[1] International Atomic Energy Agency, Critical groups and biosphere in the context of radioactive waste disposal, IAEA-TECDOC-1077, Fourth report of the working group on principles and criteria for radioactive waste disposal 1999.

[2] International Atomic Energy Agency, The Principles of Radioactive Waste Management, Safety Series No. 111-F, IAEA, Vienna 1995.

[3] International Commission on Radiological Protection, Publication 821999.

[4] Clarke, R.H., The recommendations of the ICRP on radioactive waste management, IAEA et al safety of radioactive waste management Int. Conf., Spain, Mar 13-17 2000.

[5] International Atomic Energy Agency, Long term releases from solid waste disposal facilities: the reference biosphere concept, Working material, Draft TECDOC, Biomass Theme 1, working document: BIOMASS/T1/WD01, Vienna, 1999.

[6] International Atomic Energy Agency, Example reference biosphere 2A: agricultural well, constant biosphere, Working material, Draft TECDOC, Biomass Theme 1, working document: BIOMASS/T1/WD08, Vienna, 2000.

[7] International Atomic Energy Agency, Safety Series No. 57, Vienna, IAEA, 1986.

[8] Eckerman, K.F. DFACTS: A code to preview the dosimetric data of ICRP publication 30, parts 1-4 and of the Federal Guidance Report 12, Software, Oak Ridge, TN, 1994. 